\section{KẾT LUẬN}

Kết quả của nghiên cứu đã cho thây mức độ hài lòng chung của người bệnh nội trú tại Trung tâm Thần kinh Bệnh Viện Bạch Mai với giao tiếp của điều dưỡng là cao. Sự hài lòng của người bệnh là một tiêu chí có ý nghĩa trong đánh giá chất lượng của chăm sóc điêuu dưỡng, Để nâng cao sự hài lòng của người bệnh cũng như đảm bảo chất lượng trong chăm sóc điêu dưỡng thì các kỹ năng giao tiếp điều dưỡng nên được đào tạo một cách hợp lý.

\section{TÀI LIÊU THAM KHẢO}

1. Thành, Đ.N., Mối liên quan giữa giao tiếp của điều dưỡng và sự hài lòng người bệnh của bệnh nhân nội trú tại bệnh viện a thái nguyên Tạp chí khoa học và cống nighệ $8 \dot{9}(01) / 1,2011$.

2. Ozsoy, S.A., Ozgur G. \& Akyol, D, Patient expectations and Satisfaction with nursing care in
Turkey: A Literature review. International. Nursing Review, 24, 2007.

3. Thành, N.Đ., Sư hài lòng của người bênh nôi trú về chất lượng chăm sóc sức khỏe tai các bệnh viện tỉnh Hòa Bình Nghiên cứu đề tài cấp cơ sở Trường Đại học y tế công cộng Hà Nôi 2006.

4. Soạn, H.T., Đánh giá sự hài lòng của người bệnh và người nhà người bệnh đối với công tác KCB tại một số bệnh viện tại phú tho Kỷ yểu các đề tài nghiên cứu khoa học điêu dưỡng . Hội nghị khoa học điều dưỡng lần thứ III, 2007.

5. Trang, H.Đ., "Đánh giá sự hài lòng của người bênh tại khoa Khám bênh bệnh viện Bạch Mai. luận vắn tốt nghiệp Đaii học Thăng Long Hà Nội, 2010.

6. Phước, N.N.., Đánh giá sự hài lòng của người bệnh nội trú và người nhà người bệnh về chất lượng dịch vụ y tế taii viện Tim mạch - Bệnh Viện Bạch Mai Hà Nội 2014.

7. Lam, Đ.T., Khảo Sát Sự Hài Lòng của người bệnh về dịch vư chăm sóc điêu dưỡng tại Bệnh viện $Y$ học cổ truyền Trung ương. khóa luận tốt nghiệp cử nhân Y khoa Đại học Y Hà Nội 2016.

\title{
THỰC TRANG MẮC BÊNNH BỤI PHỔI THAN CỦA NGƯờI LAO ĐộNG TẠI CÔNG TY CỔ PHẦn THAN VÀNG ANH, QUẢNG NINH NĂM 2021
}

\author{
Khương Văn Duy'1, Nguyễn Thị Quỳnh' ${ }^{1}$, \\ Khương Phương Thủy ${ }^{2}$, Đặng Thị Trang ${ }^{1}$, Nguyễn Thanh Thảo

\section{VANG DANH COAL JOINT STOCK} \\ COMPANY, QUANG NINH IN 2021 \\ Objective: The study aimed to describe the
}

\section{TÓM TẮT}

Mục tiêu: xác định tỷ lệ hiện mắc bệnh bụi than của người lao động tại Công ty cổ phân than Vàng Danh, Quảng Ninh năm 2021. Phương pháp nghiên cứu: nghiên cứu cắt ngang trên 1992 người lao đông tiếp xúc trực tiếp với bụi than tại Công ty cổ phần than Vàng Danh, Quảng Ninh năm 2021. Kết quả: tỷ lê mắc bệnh bụi than chiếm 15,8\%, trong đó thể biến chứng là $2,9 \%$. Tỷ lệ mắc bênh bui phổi than ở nam giới là $16,2 \%$, hơn một nửa $(56,6 \%)$ người mắc bệnh ở nhóm tuổi 30-39, nhóm tuổi nghề có tỷ lệ mắc bệnh cao nhất là 11-15 năm. Đa số đám mớ nhỏ có kích thước $p / p(85,1 \%)$ và mật độ tổn thương ở nhóm 1 $(60,6 \%)$. Kết luận: phần lớn đối tượng nghiên cứu không mắc bệnh bụi phổi than. Trong nhóm mắc bệnh bụi phổi than hầu hết là thể đơn thuần.

Tư khóa: thực trạng mắc bệnh, bệnh bụi phổi than, Công ty cổ phần than Vàng Danh

\section{SUMMARY}

\section{THE PREVALENCE OF OF COAL WORKERS'} PNEUMOCONIOSIS AMONG WORKERS AT

\author{
${ }^{1}$ Viện Đào tạo Y học dự phòng và Y tế công cộng, \\ trường Đại hoc Y Hà Nội \\ 2Trương đại hoc RMIT, Australia \\ Chịu trách nhiệm chính: Khương Văn Duy \\ Email: nguyenthiquynhhmu@gmail.com \\ Ngày nhận bài: 24.6.2021 \\ Ngày phản biên khoa hoc: 17.8.2021 \\ Ngày duyệt bài: 25.8.2021
} prevalence of coal workers' pneumoconiosis among workers at Vang Danh Coal Joint Stock Company, Quang Ninh in 2021. Methods: a cross-sectional study on 1992 workers exposed directly to coal dust at Vang Danh Coal Joint Stock Company, Quang Ninh in 2021. Results: The prevalence of coal workers pneumoconiosis was $15.8 \%$, in which, progressive massive fibrosis was $2.9 \%$, male rate was $16.2 \%$, more than a half $(56.6 \%)$ of those from 30 to 39 year olds and the work experience from 11 to 15 years was the highest rate. The majority of lesions with small opacity size was $\mathrm{p} / \mathrm{p}(85.1 \%)$ and small opacities density in category 1 (60.6\%). Conclusion: Most workers did not suffer from coal workers' pneumoconiosis, most of them were mild.

Keyworks: prevalence, coal wokers' pneumoconiosis, Vang Danh Coal Joint Stock Company

\section{I. ĐẶT VẤN ĐỀ}

Ngành khai thác than đóng vai trò quan trọng trong nền kinh tế quốc dân ở Việt Nam và tạo công ăn việc làm cho nhiều người lao động. Tuy nhiên khai thác than là ngành lao động nặng nhọc luôn chứa đựng các yếu tố nguy hiểm và độc hại cho người lao động như trớn trượt, sập hẩm lò và nguy cơ mắc bệnh bụi phổi than. Bệnh bụi phổi than là một bệnh nghề nghiệp xuất hiện ở những người lao động tiếp xúc với bụi than, 
tuy nhiên bênh hiện chưa có thuốc điều trị đăc hiệu. Bệnh do phản ứng của tổ chức phổi do hít thở cộng dồn bụi than vào trong phổi phát triển chậm và đặc trưng bởi tình trang xơ hóa phổi không hồi phục và có thể dẫn đến các biến chứng nguy hiểm như bệnh phổi tắc nghẽn mạn tính, tâm phế mạn, gây tổn hại nghiêm trọng đến sức khỏe, khả năng lao động và kinh tế 1 .

Hiện nay các bệnh nghề nghiệp như bệnh bụi phổi silic, bệnh bụi phổi than ngày càng được quan tâm, các nghiên cứu cũng được thực hiện nhiều hơn. Năm 2013, tại Trung Quốc tỷ lệ mắc bênh bự phổi ở công nhẩn khai thác than hầm lò là $31,8 \%$, khai thác than lộ thiên $27,5 \%$, công nhân vừa khai thác hầm lò và lộ thiên tỷ lệ mắc là $24,2 \%$ và làm công việc hỗ trợ người khai thác than là 2,6\%2ㄹ tại Mỹ (2010) nguy cơ mắc bệnh bụi phổi ở công nhân khai thác than hầm lò chiếm tới $48 \%^{3}$. Tại Việt Nam đã có một số nghiên cứu đánh giá thực trạng mắc bệnh bụi phổi than như tỷ lê mắc tại mỏ đá Núi Hồng, Thái Nguyên là $40 \%{ }^{4}$, tại Công ty cổ phần than Tây Nam đá mài là $28,5 \%{ }^{5}$. Tuy nhiên các nghiên cứu về bệnh bụi phổi than vẫn còn hạn chế. Mă̆t khác, ở nước ta đã triển khai chương trình "phòng chống và loại trừ bệnh bụi phổi silic" cần thiết phải triển khai tiếp chương trình phòng chống và loại trừ bệnh bụi phổi than nhằm cải thiện chất lượng của sống cho người lao động tiếp xúc với bụi than và gia đình họ, cũng như cải thiện năng lực cạnh tranh giữa các công ty khai thác than. Do chúng tôi tiến hành nghiên cứu với đề tài: "Thực trang mắc bênh bụi phổi than của người lao động tại Công ty cổ phần than Vàng Danh, Quảng Ninh năm 2021", với muc tiêu: xác định tỷ lệ hiện hiên mắc bênh bui than của người lao động tại Công ty cổ phần than Vàng Danh, Quảng Ninh năm 2021.

\section{II. ĐỐl TƯƠNG VÀ PHƯƠNG PHÁP NGHIÊN CỨU}

2.1. Đối tượng nghiên cứu: Người lao động đang làm việc tại Công ty cổ phần than Vàng Danh từ tháng 10 năm 2020 đến 31 tháng 5 năm 2021 và tiếp xúc trực tiếp với bụi than.

\section{* Tiêu chuân lưa chon}

- Người lao động đã làm việc tại các Công ty thời gian từ 1 năm trở lên.

- Trước đây đã từng làm công tác trực tiếp tiếp xúc với bụi than nhưng hiện tại làm cổng tác quản lý.

- Đồng ý tham gia nghiên cứu.

- Chất lượng phim chụp bụi phổi theo phân loại của ILO - 2000, ILO - 2011 đạt từ loại 1 đến loại 3.

\section{* Tiêu chuẩn loai trừ}

- Lao động hợp đồng theo thời vụ.

- Có thầm niên nghề nghiệp dưới 1 năm.

- Không đồng ý tham gia nghiên cứu.

- Chất lượng phim chụp lồng ngực loại 4 (theo hướng dẫn sử dụng bảng phân loại quốc tế ILO - 2000 phim XQ các bệnh bụi phổi).

2.2. Địa điểm nghiên cứu: Công ty cổ phần than Vàng Danh, tỉnh Quảng Ninh.

2.3. Thời gian nghiên cứu: Nghiên cứu tiến hành từ tháng 10/2020 đến 31 tháng 5/2021.

\subsection{Phương pháp nghiên cứu}

* Thiết kế nghiên cứu: Thiết kế nghiên cứu áp dụng trong đề tài này là mô tả cắt ngang

* Cõ mẫu và kỹ thuật chọn mẫu nghiên cứu

- Toàn bộ người lao động thuộc công ty than Vàng Danh đủ tiêu chuẩn lựa chọn được chon vào nghiên cứu. Các đối tượng được phỏng vấn, khám sức khỏe và chụp Xquang phim lồng ngực kỹ thuật số. Do có một số đối tượng vắng mặt, và chất lượng phim lồng ngực không đạt, thực chất còn 1992 đối tượng tham gia nghiên cứu.

\section{* Biến số và chỉ số nghiên cứu}

Biến số độc lập: giới, tuổi đời, tuổi nghề, mật độ đám mờ nhỏ, một độ đám mờ lớn, kích thước đám mờ lớn.

- Biến số phụ thuộc: mắc bệnh bụi phổi than theo giới, tuổi đời, tuổi nghề

\section{* Công cu thu thâp thông tin}

- Bộ câu hỏi nghiên cứu: nội dung bô câu hỏi xây dựng dựa trên mục tiêu và các biến số, chỉ số nghiên cứu

- Khám lâm sàng và chụp phim $X$ quang: tổn thương đám mờ nhỏ, đám mờ lớn, mât độ đám mờ... theo phiếu đọc phim bụi phổi của ILO - 2000.

\section{* Kỹ thuật thu thập thông tin}

- Số liệu được thu thập trực tiếp bằng phương pháp phỏng vấn để thu thập các thông tin chung của đối tượng nghiên cứu

- Khám lâm sàng và chụp phim $X$ quang bụi phổi $35 \times 43 \mathrm{~cm}$ và đọc phim Xquang bui phổi theo tiêu chuẩn ILO - 2000 để chẩn đoán tình trạng mắc bệnh bụi phổi than.

\section{* Quản lý và xứ lý thông tin:}

- Số liệu sau khi thu thập xong được làm sach ngay, loại đi các phiếu khồng đủ tiêu chuẩn, sau đó được nhập liệu bằng phần mềm EPIDATA 3.1 và chuyển sang phần mêm SPSS 20.0 để phân tích để cho ra các bảng tần số về thông tin chung, mật độ và kích thước đám mờ nhỏ, tỷ lệ mắc bệnh bụi phổi than theo tuổi, giới, tuổi nghề.

\subsection{Sai số và khống chế sai số}

- Sai số hệ thống: sai số nhớ lại, để hạn chế sai số này bộ câu hỏi nghiên cứu thiết kể trước khi điều tra đối tượng phải được hỏi thử và chỉnh 
sửa phù hợp với ngôn từ, ngắn gọn giúp đối tượng điều tra trả lời chính xác. Điêu tra viên phải được tập huấn trước khi tiến hành nghiên cứu, đảm bảo hiểu rõ phiếu nghiên cứu, ngôn ngữ linh hoạt.

- Sai số nhập số liệu: 2 người nhập liệu trong đó 1 người đọc phiếu, một người vào máy tính. Vừa nhập số liệu vừa kiểm tra độ chính xác của nhập sổ liệu và kiểm tra lại số liệu đã nhập một lần nữa để tránh sai sót. Sau khi kiểm tra xong phần nhập liệu, bộ số liệu sẽ chuyển sang phần mềm SPSS 22.0 để phân tích.

2.6. Đạo đức nghiên cứu. Nghiên cứu được Hội đồng phê duyệt đề tài thông qua $(\mathrm{Q} Đ$ số 616/QĐ-ĐHYHN, ngày 2 tháng 4 năm 2021) và được sự cho phép của Tập đoàn Công nghiệp Than Khoáng Việt Nam. Đối tượng nghiên cứu có thể từ chối tham gia nghiên cứu ở bất kỳ thời điểm nào của nghiên cứu. Mọi thông tin cá nhân đều được giữ bí mật và chỉ sử dụng vào mục đích nghiên cứu.

\section{KẾT QUẢ NGHIÊN CỨU}

Bảng 1. Một số đặc điểm chung của đôi tượng nghiên cứu

\begin{tabular}{|c|c|c|}
\hline Đặc điểm & Số lượng & Tỷ lệ (\%) \\
\hline Giới tính: Nam & 1940 & 97,4 \\
\hline Nữ & 52 & 2,6 \\
\hline
\end{tabular}

\begin{tabular}{|c|c|c|}
\hline \multicolumn{3}{|c|}{ Nhóm tuối đời (tuối) } \\
\hline$<30$ & 226 & 11,3 \\
\hline $30-39$ & 1128 & 56,6 \\
\hline $40-49$ & 514 & 25,8 \\
\hline$\geq 50$ & 124 & 6,2 \\
\hline Tuối đời (tuối) & \multirow{2}{*}{\multicolumn{2}{|c|}{$\frac{\text { Trung bình } \pm \text { SD }}{37,3 \pm 6.8}$}} \\
\hline & & \\
\hline \multicolumn{3}{|c|}{ Nhóm tuối nghề (năm) } \\
\hline$<5$ & 111 & 5,6 \\
\hline $5-10$ & 398 & 20,0 \\
\hline $11-15$ & 712 & 35,7 \\
\hline $16-20$ & 233 & 11,7 \\
\hline $21-25$ & 293 & 14,7 \\
\hline $26-30$ & 145 & 7,3 \\
\hline$>30$ & 100 & 5,0 \\
\hline Tuổi nghề & \multirow{2}{*}{\multicolumn{2}{|c|}{$\begin{array}{c}\text { Trung bình } \pm \text { SD } \\
15,6 \pm 7,6\end{array}$}} \\
\hline (năm) & & \\
\hline Tống & 1992 & 100 \\
\hline
\end{tabular}

Trong tổng số 1992 đối tượng nghiên cứu hầu hết là nam giới $(97,4)$. Tuổi trung bình của đối tượng nghiên cứu là $37,3 \pm 6,8$ tuổi với đa số có độ tuổi từ 30-đến 39 , khoảng $1 / 4$ có độ tuổi từ 40 đến 49 tuổi, 11,3\% nhỏ hơn 30 tuổi và chỉ $6,2 \%$ có độ tuổi từ 50 trở lên. Trung bình tuổi nghề của người lao động là 15,6 \pm 7,6 năm, nhóm tuổi nghề từ 11 - 15 năm có tỷ lệ cao nhất $(35,7 \%)$, thấp nhất là nhóm tuổi nghề từ 30 năm trở lên $(5,0 \%)$.

Bảng 2. Tỷ lệ mắc bệnh bụi phổi than theo tuổi và giới

\begin{tabular}{|c|c|c|c|c|c|c|c|}
\hline \multirow{3}{*}{\multicolumn{2}{|c|}{ Đặc điểm }} & \multicolumn{4}{|c|}{ Mắc bệnh bụi phối than } & \multirow{2}{*}{\multicolumn{2}{|c|}{ Tổng }} \\
\hline & & \multicolumn{2}{|c|}{ Có } & \multicolumn{2}{|c|}{ Không } & & \\
\hline & & $\mathbf{n}$ & $\%$ & $\mathbf{n}$ & $\%$ & $\mathbf{n}$ & $\%$ \\
\hline \multirow[t]{4}{*}{ Tuối: } & $<30$ tuối & 3 & 1,3 & 223 & 98,7 & 226 & 11,3 \\
\hline & $30-39$ tuổi & 125 & 11,1 & 1003 & 88,9 & 1128 & 56,6 \\
\hline & $40-49$ tuô̂i & 161 & 31,3 & 353 & 68,7 & 514 & 25,8 \\
\hline & $\geq 50$ tuổi & 26 & 21,0 & 98 & 79,0 & 124 & 6,2 \\
\hline \multirow[t]{3}{*}{ Giời: } & Nam & 315 & 16,2 & 1625 & 83,8 & 1940 & 97,4 \\
\hline & Nũ̃ & 0 & 0,0 & 52 & 100,0 & 52 & 2,6 \\
\hline & Tống & 315 & 15,8 & 1677 & 84,2 & 1992 & 100,0 \\
\hline
\end{tabular}

Tỷ lệ mắc bệnh bụi phổi than ở các đối tượng tham gia nghiên cứu là 15,8\% trong đó tăng dần từ nhóm tuổi dưới 30 đến nhóm tuổi 40 - 49 sau đó tỷ lệ giảm còn $21,0 \%$. Sự khác nhau về tỷ lệ mắc bệnh bụi phổi than theo nhóm tuổi rất có ý nghĩa thống kê (Fisher's Exact test: 153,507, p = 0,0001). Tuổi trung bình mắc bệnh bụi phổi than

là $41,4 \pm 6,1$ tuối, tuối mắc thấp nhất là 24 tuổi, tuổi mắc cao nhất là 58 tuổi. Bảng kết quả cũng cho thấy $16,2 \%$ nam giới mắc bệnh bụi phổi than, nữ không có đối tượng nào bị mắc bệnh bụi phổi than. Sự khác nhau về tỷ lệ mắc bệnh bụi phổi than ở hai nhóm đối tượng có ý nghĩa thống kê (Fisher's Exact test: 18,162, p = 0,0001).

Bảng 3. Tỷ lệ mắc bệnh bưi phổi than theo nhóm tuổi nghề

\begin{tabular}{|c|c|c|c|c|c|c|}
\hline \multirow{2}{*}{ Thâm niên } & \multicolumn{4}{|c|}{ Mắc bệnh bụi phối than } & \multicolumn{2}{c|}{ Tổng } \\
\cline { 2 - 6 } & \multicolumn{3}{|c|}{ Cón } & \multicolumn{2}{c|}{ Không } & \multicolumn{2}{c|}{ \% } \\
\cline { 2 - 6 } & $\mathbf{n}$ & $\mathbf{0}$ & $\mathbf{0}$ & $\mathbf{n}$ & $\mathbf{\%}$ \\
\hline $5-10$ năm & 3 & 2,7 & 108 & 87,3 & 111 & 5,6 \\
$11-15$ năm & 11 & 2,8 & 387 & 87,2 & 398 & 20,0 \\
\hline
\end{tabular}


VIETNAM MEDICAL JOURNAL N01 - SEPTEMBER - 2021

\begin{tabular}{|c|c|c|c|c|c|c|}
\hline $16-20$ năm & 46 & 19,7 & 187 & 80,3 & 233 & 11,7 \\
$21-25$ năm & 94 & 32,1 & 199 & 67,9 & 293 & 14,7 \\
26 - 30 năm & 45 & 31,0 & 100 & 69,0 & 145 & 7,3 \\
$\geq 31$ năm & 21 & 21,0 & 79 & 79,0 & 100 & 5,0 \\
\hline Tống & 315 & 15,8 & 1677 & 84,2 & 1992 & 100,0 \\
\hline
\end{tabular}

Tỷ lệ mắc bệnh bụi phối than tăng dân từ nhóm thâm niên < 5 năm đếm nhóm tuối $21-25$ năm, sau đó giảm ở nhóm tuổi từ 26 đến trên 31 năm. Sự khác nhau về thâm niên mắc bênh bưi than rất có ý nghĩa thống kê (Fisher's Exact test: 165,324, p =0,0001). Thâm niên trung bình mắc bệnh bụi phổi than là 19,9 \pm 6,8 năm.

Bảng 4. Phân bố mắc bệnh bụi phổi than theo kích thước và mật độ đám mờ nhỏ

\begin{tabular}{|c|c|c|}
\hline Đắc điếm & n & $\%$ \\
\hline \multicolumn{3}{|c|}{ Kích thước đám mờ nhỏ } \\
\hline $\mathrm{p} / \mathrm{p}$ & 268 & 85,1 \\
\hline $\mathrm{p} / \mathrm{q}$ & 1 & 0,3 \\
\hline $\mathrm{q} / \mathrm{q}$ & 32 & 10,2 \\
\hline $\mathrm{r} / \mathrm{r}$ & 1 & 0,3 \\
\hline $\mathrm{s} / \mathrm{p}$ & 9 & 2,9 \\
\hline s/s & 1 & 0,3 \\
\hline$t / p$ & 2 & 0,6 \\
\hline$t / t$ & 1 & 0,3 \\
\hline \multicolumn{3}{|c|}{ Mật độ đám mờ nhỏ } \\
\hline Nhóm $1(1 / 0-1 / 2)$ & 191 & 60,6 \\
\hline Nhóm $2(2 / 1-2 / 3)$ & 74 & 23,5 \\
\hline Nhóm $3(3 / 2-3 /+)$ & 50 & 15,9 \\
\hline Cộng & 315 & 100,0 \\
\hline
\end{tabular}

Tỷ lệ đám mờ nhỏ có kích thước $p / p$ chiếm đa số $(85,1 \%)$, tiếp theo là q/q $(10,2 \%)$. Ngoài đám mờ nhỏ tròn đều, trên phim chup phổi của các đối tượng mắc bênh bụi phổi than còn có đám mờ nhỏ không tròn đều nhưng chiếm tỷ lệ thấp. Bảng kết quả cũng chỉ ra rằng tỷ lệ đám mờ nhỏ có mật độ nhóm $1(1 / 0-1 / 2)$ chiếm tới $60,6 \%$, tiếp theo là nhóm $2(2 / 1-2 / 3)$ chiếm $23,5 \%$ và nhóm $3(3 / 2-3 /+)$ chiếm $15,9 \%)$.

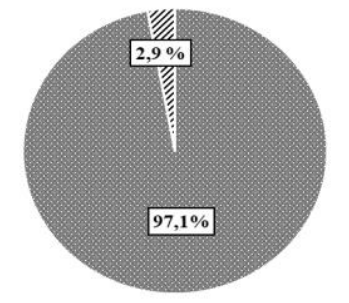

• Thể đơn thuần "Thể biến chứng

\section{Biểu đồ 1. Phân loại bệnh bụi phổi than của} đôi tướng nghiên cứu

Trong tổng số 315 đối tương mắc bênh bui phổi than, tỷ lệ mắc bệnh bụi than thể biến chứng chiếm 2,9\%.

\section{BÀN LUÂN}

Công ty cổ phần than Vàng Danh làm nhiệm vụ khai thác, chế biến, nhập, kinh doanh than và vận tải than... thu hút cả lao động nam và nữ. Ở nhóm người lao động tiếp xúc trực tiếp với bụi than là nam tham gia nghiên cứu ở độ tuổi từ 30 tuổi trở lên chiếm đa số $(88,6 \%)$, ở nhóm lao động nữ giới từ 30 trở lên cũng chiếm phần lớn $(92,3 \%)$ nhưng ở nhóm tuổi từ 50 trở lên tỷ lệ này chỉ chiếm $5,8 \%$. Điều này có thể giải thích sau tuổi 50 , phụ nữ rơi vào thời kỳ mãn kinh, sức khỏe không còn tốt như trước, không còn phù hợp với những công việc nặng nhọc như ngành than, kéo theo tỷ lệ lao động nữ ở độ tuổi này sẽ giảm. Tuổi nghề của người lao động 11 - 15 năm chiếm tỷ lệ cao nhất $(35,7 \%)$ từ 5 năm trở xuống chỉ chiếm tỷ lệ $5,6 \%$ tổng số người lao động tham gia nghiên cứu. Ở cả nhóm nam và nữ tuổi nghề $\geq 31$ năm chiếm tỷ lê thấp nhất $(5,1 \%)$ và cũng tương tự ở nhóm nữ $(3,8 \%)$. Có sự khác nhau về tuối nghề giữa nam và nữ do đặc điểm sinh lý, sức khỏe của nữ giới thường kém dẻo dai, sức bền giảm theo thời gian cùng với giai đoạn mãn kinh nên có tỷ lệ gắn bó với nghề không được lâu dài như nam giới. Khi tuổi càng cao nữ giới có xu hướng chuyển sang những công việc nhẹ nhàng hơn, phù hợp với sức khỏe hơn.

Trên thế giới có nhiều nghiên cứu về tỷ lệ mắc bệnh bụi phổi than, tỷ lệ này khác nhau giữa các vùng, giữa đăc điểm khai thác hầm lò, lộ thiên, khác nhau giữa giới tính, giữa tuổi đời, tuổi nghề, tình trạng hút thuốc hay bệnh nền kèm theo. Kết quả nghiên cứu của chúng tôi cho thây tỷ lệ mắc bênh bụi phổi than là 15,8\%. Kết quả của chúng tồi thấp hơn nhiều so với nghiên cứu của Laney AS và cộng sự (2010) cho thấy nguy cơ mắc bệnh bụi phổi ở công nhân khai thác than hầm lò chiếm tới $48 \%^{3}$. So với các nghiên cứu trong nước, tỷ lệ mắc bệnh bụi phổi than trong nghiên cứu của chúng tổi cũng thấp hơn tại mỏ đá Núi Hồng, Thái Nguyên là $40 \%{ }^{4}$, và Công ty cổ phần than Tây Nam đá mài là $28,5 \%{ }^{5}$. Sự chênh lệch này có thể do địa điểm nghiên cứu khác nhau với các đặc điểm về công việc, bảo hộ lao động, địa hình lao động, điều kiển khí hậu, môi trường khác nhau. Sự khác nhau này cũng do sự khác nhau về mẫu nghiên cứu, và chụp phim Xquang phổi chỉ tập trung vào những đối tượng làm trực tiếp với nơi có 
nguy cơ cao, còn những đối tượng trước đó đã làm việc, tiếp xúc với bụi than, chuyển sang bộ phận khác không được chụp phim phổi.

Về tỷ lệ mắc bệnh bụi phổi than theo giới, trong nghiên cứu của chúng tôi nam bị mắc $16,2 \%$ và nữ không có trường hợp nào mắc và tỷ lệ mắc bệnh bụi phổi than giữa hai nhóm đối tượng này khác nhau có ý nghĩa thống kê (Fisher's Exact test $=18,162 ; \mathrm{p}=0,0001$ ). Trong khi nghiên cứu của Shen và cộng sự lại chưa tìm thấy sự khác nhau về tỷ lệ mắc bệnh bụi phổi than giữa giới nam và nữ. Về tuổi đời: kết quả nghiên cứu của chúng tôi cho thấy nhóm tuổi có tỳ lệ người lao động mắc bệnh bụi phổi than nhiều nhất là các nhóm tuổi 30 - 39 và từ 40 - 49 tuổi). Kết quả nghiên cứu của Shen và cộng sự cho thấy tuổi bị mắc bệnh bụi phổi than có thể gặp ở mọi lứa tuổi và việc phát bệnh phụ thuộc vào thâm niên và nồng độ bui than đã tiếp xúc, phụ thuộc thời gian bắt đâu làm việc tại các mỏ than. Tỷ lệ mắc bệnh tăng lên khi tiếp xúc với bụi than hổ hấp nồng độ lớn. Điều này có thể lý giải do đây là công việc nặng nhọc những người lao động có tuổi đời càng cao, tiếp xúc với bụi than càng nhiều có tỷ lệ mắc bệnh bụi phổi than càng cao và cao hơn so với những người lao động ở nhóm tuổi trẻ hơn. Về tuổi nghề kết quả nghiên cứu của chúng tôi cho thấy tỷ lệ hiện mắc bệnh bụi than ở Công ty cổ phần than Vàng Danh tăng dần theo nhóm tuổi nghề, nhóm tuổi nghề có tỷ lệ mắc bệnh nhiều nhất là nhóm 21 25 và 26-30. Tuổi nghề trung bình mắc bệnh bụi phổi là $19,9 \pm 6,8$ năm. Kết quả này thẩp hợn nghiên cứu của Lei Han và cộng sự về trung bình tuổi đời mắc bệnh bụi phổi than. Sự khác nhau này có lẽ do cỡ mẫu nghiên cứu cũng như tình trạng khai thác than, kỹ thuật khai thác và công nghệ khai thác than khác nhau tùy từng nước.

Nghiên cứu của chúng tôi cho thây đa số là tổn thương đám mờ nhỏ kích thước $\mathrm{p} / \mathrm{p}$ $(85,1 \%)$, còn đám mờ nhỏ kích thước $q / q$ chiếm $10,2 \%$, kết quả này có sự khác biệt với nghiên cứu của Carlos Humberto Torres Rey và cộng sự8 tỷ lệ đối tượng mắc bệnh bụi phổi với kích thước đám mờ nhỏ $\mathrm{p} / \mathrm{p}$ chung cho cả hai vùng chỉ chiếm $10,0 \%$, trong khi đó đám mờ có kích thước q/q chiếm 39,4\%. Về mật độ đám mờ, trong nghiên cứu của chúng tôi ghi nhận tất cả mật độ đám mờ từ trong đó mật độ đám mờ nhóm 1 chiếm đa số, mật độ đám mờ nhóm 2 chiếm khoảng $1 / 4$ và nhóm 3 chiếm tỷ lệ $15,9 \%$. Kết quả nghiên cứu của chúng tôi tươning đồng với kết quả của Lei Han và cộng sự . Hầu hết đối tượng mắc bệnh bui phổi than trong nghiên cứu của chúng tôi là thể đơn thuần, chỉ có 2,9\% là thể biến chứng, tỷ lệ này cao hơn nghiên cứu của Laney AS và cộng sự 9 Sự khác biệt này có thể do môi trường làm việc khác nhau, tuổi nghề của đối tượng nghiên cứu khác nhau nên có thể tiếp xúc với nồng độ bụi than khác nhau.

\section{KẾT LUÂN}

Tỷ lệ hiện mắc bệnh bụi phổi than chiếm $15,8 \%$, trong đó tỷ lệ mắc bệnh bụi phổi than thể biến chứng là $2,9 \%$. Đa số đám mờ nhỏ có kích thước $\mathrm{p} / \mathrm{p}(85,1 \%)$ và mật độ tổn thương ở nhóm $1(60,6 \%)$. Để giảm tỷ lệ mắc bệnh bụi phổi than, cần phải có những biện pháp cụ thể, chủ động bao gồm các biện pháp phòng hộ cá nhân, các biện pháp kỹ thuật sản xuất để cái thiện điều kiện lao động và giảm thiểu phơi nhiê̂m với bụi than cho người lao động. Đặc biệt cần kết hợp khám phát hiện bệnh nghề nghiệp cùng với khám sức khỏe định kì cho người lao động ngành than.

\section{TÀI LIỆU THAM KHẢO}

1. Bộ $Y$ tế. Bệnh bụi phổi than nghề nghiệp. Accessed Trúy cập ngày 5 tháng 3 năm 2021, https://moh.gov.vn/web/phong-chong-benh-nghenghiep/thong-tin-hoat-dong/-

/asset_publisher/xjpQsFUZRw4q/content/benh-buiphoi-than-nghe-nghi-1?

2. Shen Fuhai, Yuan Juxiang, Sun Zhiqian, et al. Risk identification and prediction of coal workers' pneumoconiosis in Kailuan Colliery Group in China: a historical cohort study. PLoS One. 2013;8(12):e82181.

3. Laney A Scott, Attfield Michael D. Coal workers' pneumoconiosis and progressive massive fibrosis are increasingly more prevalent among workers in small underground coal mines in the United States. Occupational and environmental medicine. 2010;67(6):428-431.

4. Khương Văn Duy, Nguyễn Ngọc Hông, Lê Quang Chung. Thực trang mắc bệnh bụi phổi than tại mỏ than núi Hồng, Thái Ṅguyên, năm 2018. Y học dự phòng. 2018;29(15):102-105.

5. Khương Văn Duy, Phan Mai Hương, Lê Quang Chung. Mô tả một số đặc điểm lâm sàng về bệnh đường hô hấp ở người lao động tại cổng ty cổ phần than Tay nam đá mài, Vinacomin, 2019. Y hoc dự phòng. 2019;30(4):227-230.

6. Shen $\mathbf{H N}$, Jerng JS, Yu CJ. Outcome of coal worker's pneumoconiosis with acute respiratory failure. Chest. Mar 2004;125(3):1052-8. doi:10.1378/chest.125.3.1052

7. Lei Han, Ruhui Han, Xiaoming Ji, et al. Prevalence characteristics of coal workers' pneumoconiosis (CWP) in a state-owned mine in Eastern China. International journal of environmental research and public health. 2015; 12(7):7856-7867.

8. Carlos Humberto Torres Rey, Ibañez Pinilla M, Leonardo Briceño Ayala, et al. Underground coal mining: relationship between coal dust levels and pneumoconiosis, in two regions of Colombia, 2014. BioMed research international. 2015;2015. 